\title{
Comparison of Two Generations of Systems for Digital Occlusion Examination
}

\author{
Tanya Bozhkova*(iD \\ Department of Prosthetic Dentistry, Faculty of Dental Medicine, Medical University, Plovdiv, Bulgaria
}

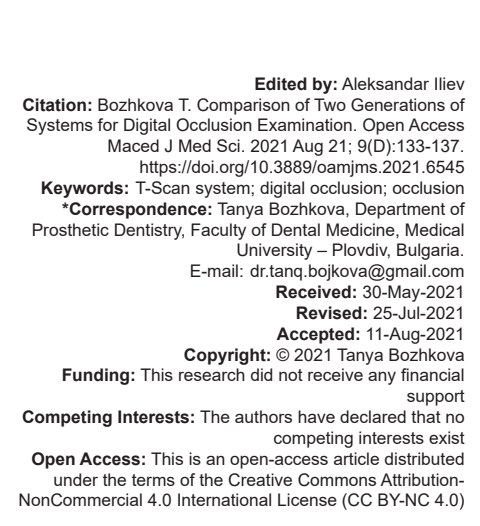

Introduction

According to the Glossary of Prosthodontic Terms, occlusion is a static relationship between the masticatory surfaces of the upper and lower teeth [1]. Occlusion can be defined very simply: it means the contacts between teeth [2].

Occlusal contacts occur when the two dental arches touch in maximum intercuspation (MIP). To achieve ideal occlusion, all lateral teeth must be in contact at the same time and the occlusal contacts must be evenly distributed [3].

The modern concept of occlusion includes the relationship between teeth, masticatory muscles, and temporomandibular joints in function and dysfunction [4], [5].

With the occurrence of preliminary contacts and occlusal-articulatory blockages, conditions are created for the occurrence of the clinical symptoms of acute or chronic trauma of the main anatomical-dental structures [6], [7] - hard dental tissues [8], [9], [10], periodontium [11], [12], masticatory muscles [13], and temporomandibular joints [14].
Physiological restoration of occlusion is important for a healthy functioning masticatory system [15].

Occlusal indicators are used in daily dental practice to study the occlusal-articulation relations [16]. Their accuracy is essential for achieving harmonious and balanced occlusal contacts, which is the ultimate goal of any dental treatment. Qualitative and quantitative methods are used to register and evaluate occlusal contacts [17]. The reliability and sensitivity of occlusal indicators depend on the thickness, strength, and elasticity of the recording materials, as well as on the conditions of the oral environment and the interpretation of the dentist [18], [19].

Quality occlusal indicators are articulation paper, articulation foil, articulation silk, wax, and impression materials. They determine only the location and number of occlusal contacts and their sequence of occurrence cannot be estimated. The strength and sequence of occlusal contacts can be determined by the quantitative method of occlusion examination [20], [21]. The technology is used in any case that requires diagnosis and treatment of occlusion.

T-Scan system and OccluSense system are digital occlusal analysis systems. The evolution of the T-Scan technology over the past 33 years had its 
beginning with T-Scan I in 1987, then T-Scan II for Windows in 1995, to T-Scan III (software versions 5, 6, and 7) in 2004 [22]. The T-Scan handpiece model was updated in 2015 as T-Scan Novus (software version 9.1) and the latest updated one being the T-Scan version 10 software version introduced in 2018 [23].

\section{Aim}

This study demonstrates the capabilities and results of two generations of systems - T-Scan III and T-Scan Novus.

\section{Materials and Methods}

For the realization of the set goal, the occlusion of a patient with the initials S.K. is examined with two systems. The patient is 43 years old with intact teeth, Angle's class I jaw relation.

The study with T-Scan III was conducted in 2015 and with T-Scan Novus in 2019 (Figure 1).

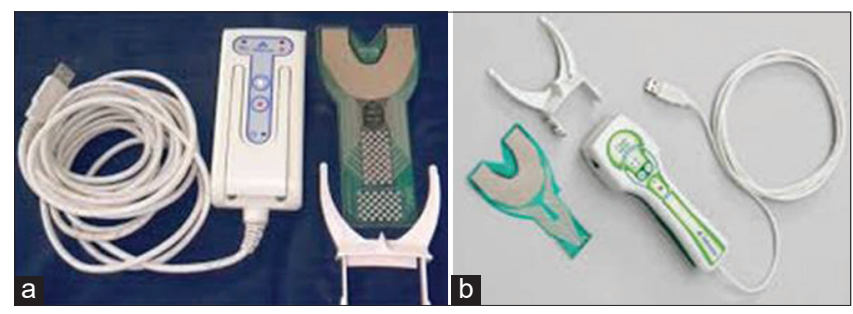

Figure 1: (a) System T-Scan III (b) System T-Scan Novus

The T-Scan system consists of a recording handle, sensor support, and a sensor. The T-Scan Novus handle has a new ergonomic design compared to older versions of the system (Figure 2). Working with it is facilitated by buttons and indicators located on its upper surface.

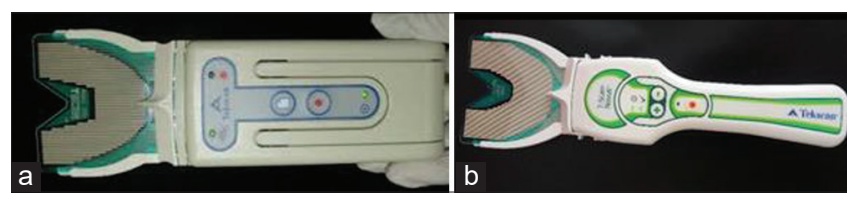

Figure 2: Recording handle (a) T-Scan III system (b) T-Scan Novus system

The sensor in both systems is $100 \mu$ thick. They are produced in two sizes - large and small (Figure 3). The latest generation sensor has a higher resolution and a different design.

The recording technique is performed as follows: The patient is positioned in a sitting position on the dental chair so that the torso and lower limbs are approximately below $90^{\circ}$. The selected sensor is placed in the corresponding size stand connected to the scanning handle. The device is placed so that the index finger of the holder is positioned between the

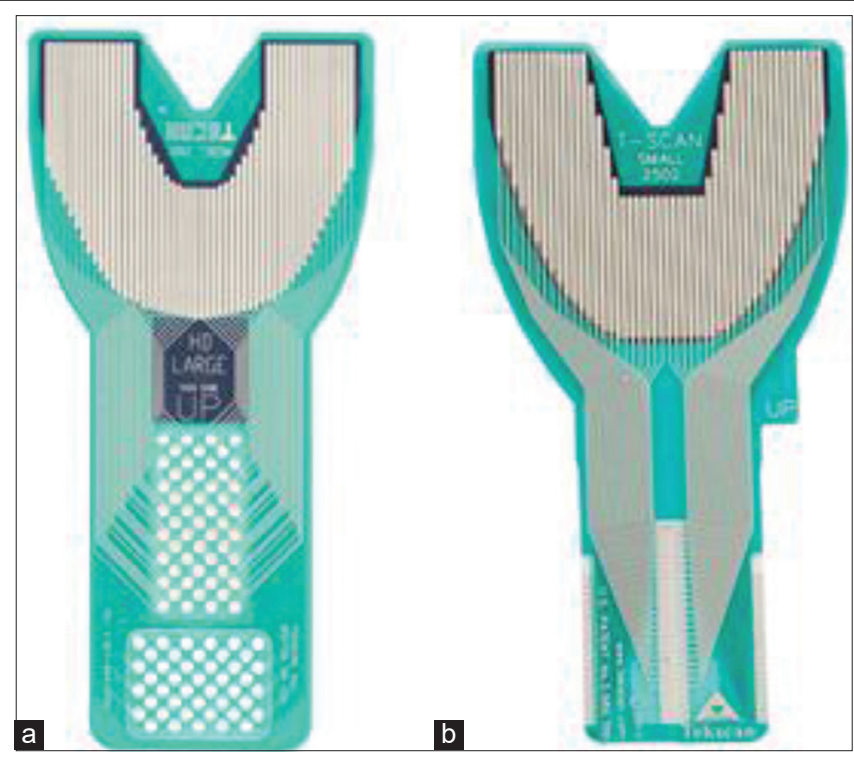

Figure 3: Sensor. (a) T-Scan III system (b) T- Scan Novus system

upper central incisors of the patient (Figure 4). To start the recording, the push-button is pressed on the handle and the patient is asked to close the lower jaw until tight contact between the teeth in centric relation.

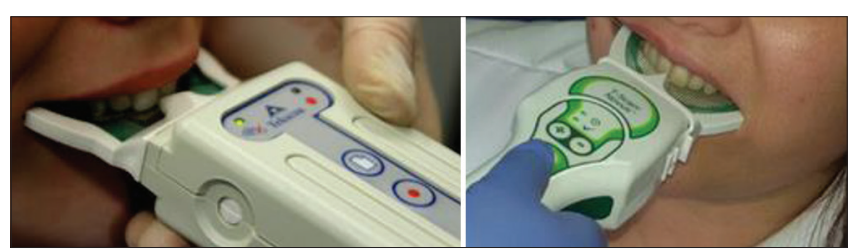

Figure 4: Proper positioning of the T-Scan system

The results obtained with the T-Scan III system are the analysis with software version 7 and those with T-Scan Novus with software version 9.1.

\section{Results and Discussion}

The software of both systems uses a graphical interface, which transforms the data obtained during the recording of the occlusion as the model of the upper dentition of the patient in T-Scan III (Figure 5) and the upper and lower dentition in T-Scan Novus (Figure 6).

Registered occlusal contacts are illustrated as $2 \mathrm{D}$ and $3 \mathrm{D}$ images of different colors. There is an option that allows the dentition to be divided into two halves - green (left) and red (right) and their corresponding forces are displayed in percentages. The dentition can be divided into anterior and posterior halves, resulting in four segments. The T-Scan Novus also shows the percentage load on each tooth.

In three-dimensional images, the registered contacts are displayed as bars of different colors and height, demonstrating the intensity of the forces that arise in them during contact. The strength of the contacts is evaluated accordingly using a color scale in 
which the strongest contacts are represented in red and the weakest in blue.

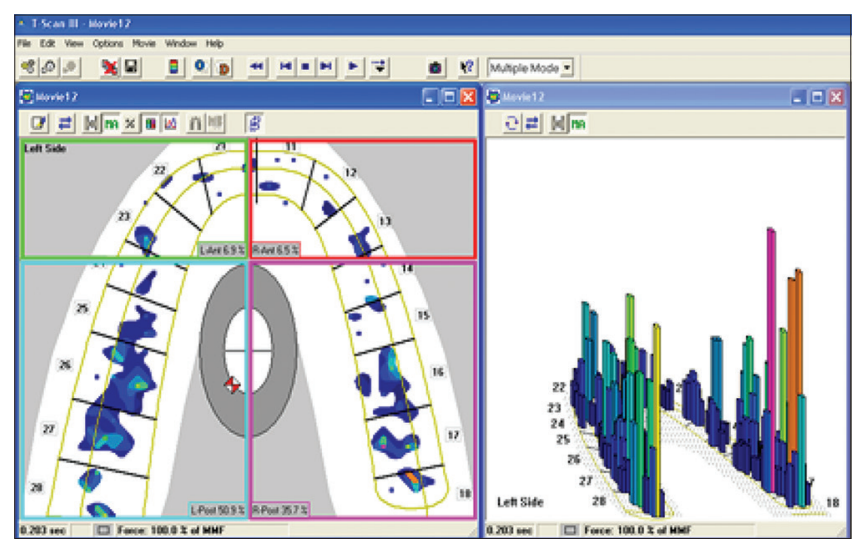

Figure 5: Dental aches in 2D and 3D view with T-Scan III system

In the study with the T-Scan III system, it was found that the forces in the MIP are, respectively, in - the left anterior segment $6.9 \%$, the right anterior segment $6.5 \%$, the left posterior segment $50.9 \%$, and the right posterior segment $35.7 \%$. When comparing the obtained values, it was found that the forces in the front sections are approximate, but the forces in the rear left segment are higher than the rear right segment. COF is the center of force target but is displaced on the left. It can be summarized that the left half of the dentition is subjected to a greater load than the right half. Also that the occlusal forces in both halves are unbalanced.

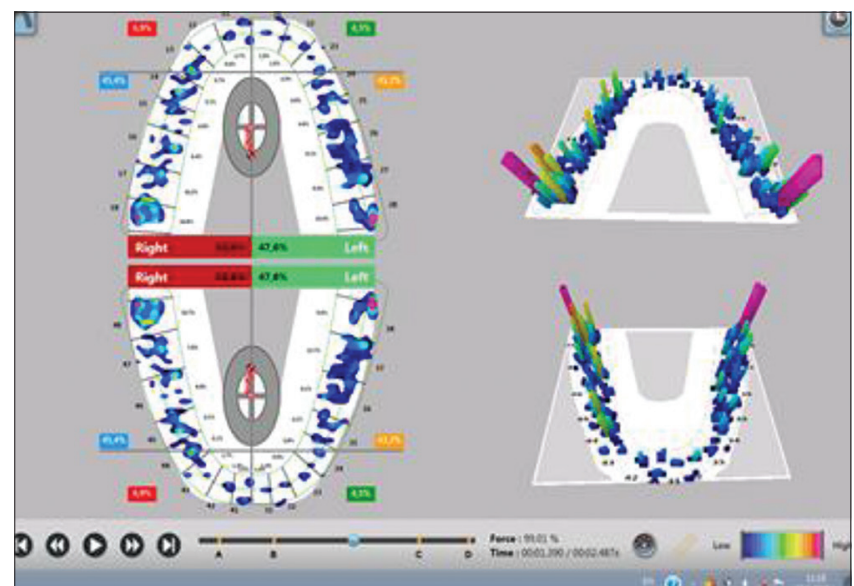

Figure 6: Dental aches in 2D and 3D view with T-Scan Novus system

In the study with the T-Scan Novus system, it was found that the forces in the MIP are, respectively, in - the left anterior segment $4.5 \%$, the right anterior segment $6.5 \%$, the left posterior segment $43.2 \%$, and the right posterior segment $45.4 \%$. This shows that the forces on the right anterior segment were higher than those in the left anterior segment and forces in the posterior segments have a minimum difference. COF is the center of force target. It is established that the forces in both halves of the dentition are balanced. To achieve perfect occlusion, all posterior teeth should make contacts simultaneously and all occlusal contacts should be balanced [3]. The T-Scan system helps in assessing the occlusion and in balancing the occlusal forces by quantitatively measuring them [24].

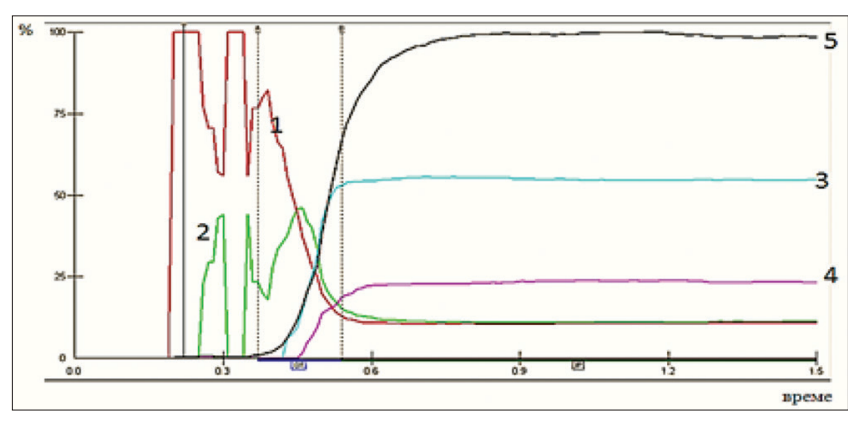

Figure 7: Graph force/time T-Scan III system

The graph force/time shows the power versus time from the first contact to the end of the movie. Each line is color-coded, according to the quadrants of the dental arch (Figure 7) or of the individual teeth, in the case of Novus (Figure 8).

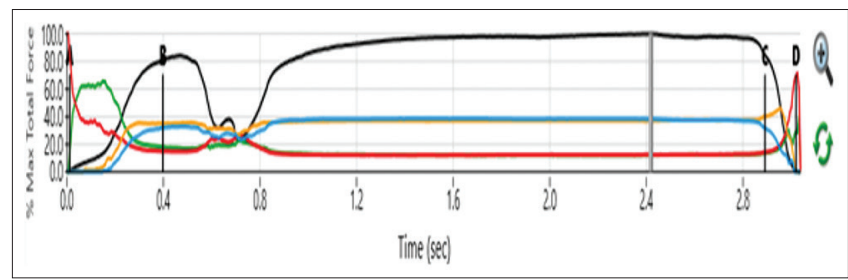

Figure 8: Graph force/time T-Scan Novus system

The software displays the time calculated in seconds from the first contact to the maximum intercussion time, the so-called occlusion time (OT). The time in seconds from maximum intercuspation to displacement of the lower jaw forward left or right is the so-called disclusion time (DT). The interval from $A$ to $B$ shows the occlusal time, and the interval from $C$ to $D$ shows the disoclusal time.

The timing table displays the patient's total occlusal bite timing, and the force applied. These lines are used to mark two separate sets of positions (frames) of the scan. The A-B increment/differential lines denote the start and end of the OT and the C-D increment/differential lines denote the start and end of the DT (Figure 9).

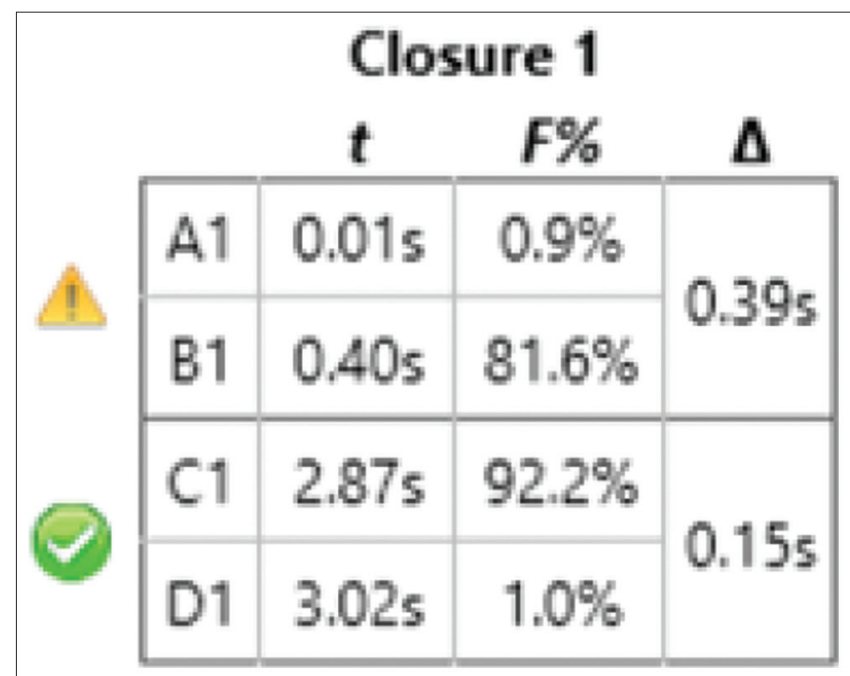

Figure 9: Timing table T-Scan Novus 
OT is $0.39 \mathrm{~s}$ and is elevated. The ideal duration of OT is $\leq 0.2 \mathrm{~s}$ [25]. The shorter the occlusal time, the faster the contact between the teeth. DT is $0.15 \mathrm{~s}$ and it is normal. The ideal duration of DT is $\leq 0.5 \mathrm{~s}$ [25].

T-Scan Novus software allows you to import digital fingerprint files of the upper and lower dentition in.stl format. The registered occlusal contacts are visualized on the scanned dentition (Figure 10).

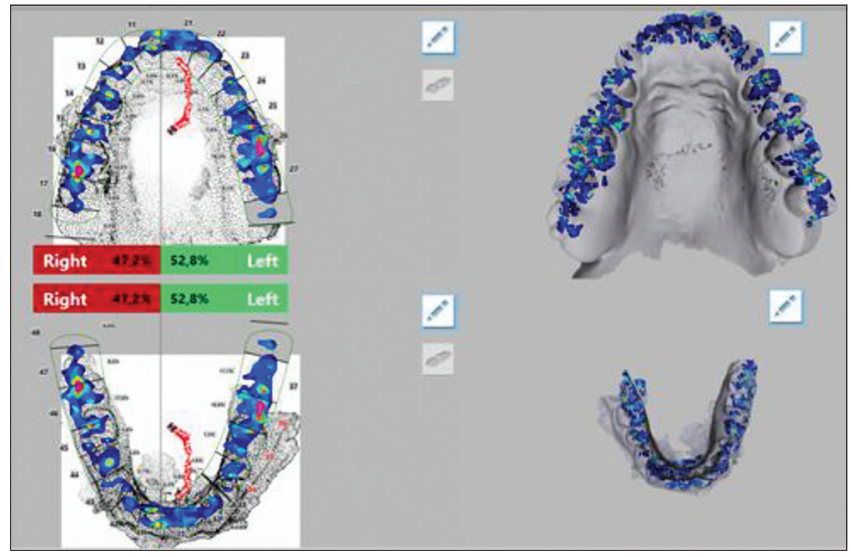

Figure 10: Digital impression overlay

The software program of the system version 9.1 provides better visualization of dental arches making it much more informative than other versions. The T-Scan system allows fast and accurate registration and analysis of occlusion.

\section{Conclusion}

The results obtained from the study with the T-Scan Novus system show that it provides valuable information about the time and location of occlusal contact, as well as the applied occlusal forces. The new and improved functions of the software provide detailed digital information about the registered occlusal-articulation relations, which improves and facilitates their analysis.

\section{References}

1. Ferro K, Morgano S, Driscoll C, Freilich M. The glossary of prosthodontic terms. J Prosthet Dent. 2017;43:57.

2. Davies S, Gray RM. What is occlusion? $\mathrm{Br}$ Dent J. 2001;191(5):235-45.

PMid:11575759

3. Korioth TW. Number and location of occlusal contacts in the intercuspal position. J Prosthet Dent. 1990;64(2):206-10. https:// doi.org/10.1016/0022-3913(90)90180-k PMid:2202820

4. Dickerson WG, Chan CA, Carlson J. The human stomatognathic system: A scientific approach to occlusion. Dent Today.
2001;20(2):100-2, 4-7.

PMid:12524854

5. Rues S, Schindler HJ, Turp JC, Schweizerhof K, Lenz J. Motor behavior of the jaw muscles during different clenching levels. Eur J Oral Sci. 2008;116(3):223-8. https://doi. org/10.1111/j.1600-0722.2008.00537.x

PMid: 18471240

6. Schmitter M, Balke Z, Hassel A, Ohlmann B, Rammelsberg P. The prevalence of myofascial pain and its association with occlusal factors in a threshold country non-patient population. Clin Oral Invest. 2007;11(3):277-81. https://doi.org/10.1007/ s00784-007-0116-1

PMid:17410385

7. Fan J, Caton J. Occlusal trauma and excessive occlusal forces: Narrative review, case definitions, and diagnostic considerations. J Periodontol. 2018;89(Suppl 1):S214-22. https://doi.org/10.1002/jper.16-0581

PMid:29926937

8. Ruiz JL. Seven signs and symptoms of the occlusal disease The key to an easy diagnosis. Dent Today. 2009;28(8):112-3.

PMid:19715074

9. Telles D, Pegoraro LF, Pereira JC. Incidence of noncarious cervical lesions and their relation to the presence of wear facets. J Esthet Restor Dent. 2006;18(4):178-83; discussion 184. https://doi.org/10.1111/j.1708-8240.2006.00015.x PMid:16911416

10. Brandini DA, Trevisan CL, Panzarini SR, Pedrini D. Clinical evaluation of the association between noncarious cervical lesions and occlusal forces. J Prosthet Dent. 2012;108(5):298303. https://doi.org/10.1016/s0022-3913(12)60180-2

PMid:23107237

11. Ishigaki S, Kurozumi T, Morishige E, Yatani H. Occlusal interference during mastication can cause pathological tooth mobility. J Period Res. 2006;41(3):189-92. https://doi. org/10.1111/j.1600-0765.2005.00856.x

PMid: 16677287

12. Zhou S, Mahmood H, Cao C, Jin L. Teeth under high occlusal force may reflect occlusal trauma-associated periodontal conditions in subjects with untreated chronic periodontitis. Chin J Dent Res. 2017;20(1):19-26.

PMid:28232963

13. Okano N, Baba K, Igarashi Y. Influence of altered occlusal guidance on masticatory muscle activity during clenching. J Oral Rehabil. 2007;34(9):679-84. https://doi. org/10.1111/j.1365-2842.2007.01762.x

PMid: 17716267

14. Abdalla HB, Clemente-Napimoga JT, Bonfante $R$, Hashizume CA, Zanelli WS, de Macedo CG, et al. Metallic crown-induced occlusal trauma as a protocol to evaluate inflammatory response in the temporomandibular joint and periodontal tissues of rats. Clin Oral Invest. 2019;23(4):190512. https://doi.org/10.1007/s00784-018-2639-z PMid:30232624

15. Baldini A, Nota A, Cozza, P. The association between occlusion time and temporomandibular disorders. J Electromyogr Kinesiol. 2015;25(1):151-4. https://doi.org/10.1016/j.jelekin.2014.08.007 PMid:25218790

16. Sharma A, Rahul GR, Poduval ST, Shetty K, Gupta B, Rajora V. History of materials used for recording static and dynamic occlusal contact marks: A literature review. J Clin Exp Dent. 2013;5(1):48-53 PMid:24455051

17. Panigrahi D, Satpathy A, Patil A, Patel G. Occlusion and occlusa indicating materials. Int J Appl Dent Sci. 2015;1(4):23-6. 
18. Zuccari AG, Oshida Y, Okamura M, Paez CY, Moore BK. Bulge ductility of several occlusal contacts measuring paper-based sheets. Biomed Mater Eng. 1997;7(4):265-70. https://doi. org/10.3233/bme-1997-7405

PMid:9408578

19. Bozhkova T. Comparative study of occlusal contact marking indicators. Folia Med. 2020;62(1):180-4. https://doi.org/10.3897/ folmed.62.e48018

20. Thumati P. The infuence of immediate complete anterior guidance development technique on subjective symptoms in Myofascial pain patients: Veried using digital analysis of occlusion (Tekscan) for analyzing occlusion: A 3 year's clinical observation. J Indian Prosthodont Soc. 2015;15(3):218-34. https://doi.org/10.4103/0972-4052.158079

PMid:26929516
21. Sutter B. Digital occlusion analyzers: A product review of T-scan 10 and occlusense. Adv Dent Technol Tech. 2019;2(1):1-31.

22. Kerstein R. Handbook of Research on Computerized Occlusal Analysis Technology Applications in Dental Medicine. Pennsylvania, United States: IGI Global; 2014. p. 1-15.

23. Tekscan. Dental; 2018. Available from: https://www.tekscan. com/dental. [Last accessed on 2021 May 21].

24. Afrashtehfar KI, Srivastava BD, Esfandiari S. A Health Technology Assessment Report on the Utility of Digital Occlusal Analyzer System T-Scan® in Temporomandibular Disorders; 2013.

25. Kerstein R, Lowe M, Harty M, Radke J. A force reproduction analysis of two recording sensors of a computerized occlusal analysis system. Cranio. 2006;24(1):15-24. https://doi. org/10.1179/crn.2006.004

PMid:16541841 